\title{
Ang Demokratikong Sistema at ang mga Modelo ng Pamumuno sa Pilipinas $^{1}$
}

\section{F. P. A. Demeterio}

\section{Introduksyon}

$\mathrm{M}$ araming paraan ang pagsusuri sa problema ng pulitika sa Pilipinas. Para sa mga moralista at ideyalista, halimbawa, maaari itong tingnan gamit ang perspektibo ng sistema ng pagpapahalaga (values) at moralidad; para sa mga materyalista naman, maaari din itong himayin gamit ang perspektibo ng pagka-di-pantay-pantay ng kayamanan at kapangyarihan (unequal wealth and power) ng ating mga mamamayan; o hindi kaya para sa mga eksperto sa sistema at istraktura, maaari din itong dalumatin gamit ang perspektibo ng ating marupok na burukrasya. Susubukan ng papel na ito na pag-aralan ang paksa sa pamamagitan ng pagsusuri sa konsepto ng pamumuno na hinihiling ng ating demokratikong sistema at sa kaparehong konseptong umiiiral naman sa kamalayan ng ating mga kababayan. Gagamitin ng pagsusuring ito, bilang teoretikal na balangkas, ang isang uri ng antropolohikal na teorya at pamamaraan na kilala bilang "kognitibong antropolohiya" (cognitive anthropology).

\section{Ang Kognitibong Antropolohiya Bilang Teoretikal na Balangkas}

Ang kognitibong antropolohiya ay umusbong mula sa mga nagtatagpong adhikain ng ilang disiplinang nagmumula sa agham pangkalikasan, agham pantao, agham pangkompyuter, at pati na sa humanidades, na lahat interesado sa pag-aaral ng kognisyon sa pamamagitan ng paghihimay ng wika. Nakatutok ang mga pagsusuri ng kognitibong antropolohiya sa intelektwal, mental, at rasyunal na mga aspeto ng partikular na kultura. Ayon kay Roy D' Andrade, isa sa mga nangungunang kognitibong antropolohista ngayon, ang teoretikal at metodolohikal na balangkas na ito ay nakatuon sa "pag-aaral sa ugnayan sa pagitan ng lipunan at kaisipan," at sumisipat sa "mga paraan kung papaano nag-iisip ang mga panlipunang

1 This paper was read at the author's Don Francsico Ortigas, Sr. Professorial Chair Lecture held at De La Salle University, Manila, Philippines, 26 March 2010. [Editor's note] 
pangkat tungkol sa mga bagay-bagay at pangyayari na bumubuo sa kanilang mundo- kasama dito ang lahat mula sa mga kongkretong bagay tulad ng mga ligaw na halaman at mga abstraktong pangyayari tulad ng panlipunang katarungan. ${ }^{2}$

Mayroong apat na sangay ang kognitibong antropolohiya: 1) semantika; 2) ang pag-aaral ng mga istraktura ng kaalaman; 3) ang pag-aaral ng mga modelo at sistema; at 4) ang pagsusuri ng diskurso, o "discourse analysis". Gagamitin ng papel na ito ang ikatlong sangay, ang pag-aaral ng mga modelo at sistema na nilalaman ng kamalayan ng mga tao sa isang lipunan. Sentral sa sangay na ito ang mga konsepto ng iskemang pangkognitibo (cognitive schema), modelong kultural (cultural model), at "script" at "scenario."

Unang iminungkahi ang ideya ng iskemang pangkognitibo ni Frederic Bartlett sa kanyang 1932 na obra na Remembering: A Study in Experimental and Social Psychology. Sa aklat na ito, ang iskemang pangkognitigo ay itinuturing bilang isang mental na istraktura na aktibong nagsasaayos sa mga nakaraang karanasan at reaksyon, para madali itong maalala ng tao paglipas ng panahon. Hinango at bahagyang binago ng kognitibong antropolohiya ang konseptong ito ni Bartlett. Kaya simula noong dekada 80 naging pangunahing sangkap ito sa pagsisilip sa sikolohiya ng isang kultura, at ngayon itinuturing bilang isa sa mga pinakamahalaga at pinakamabisang konsepto ng kognitibong antropolohiya.

Ipinaliwanag ni Ronald Casson, sa kanyang sanaysay na "Schemata in Cognitive Anthropology" na ang iskemang pangkognitibo ay mga "konseptwal na abstraksyon na namamagitan sa mga natatanggap na "stimulus" ng mga "sense organ" at mga behavioral na reaksyon," at nagsisilbing "basehan ng lahat ng pagproseso ng impormasyon ng tao, tulad ng pagdarama at pag-uunawa, kategorisasyon at pagpaplano, pagkikilala at pag-alala, pagbibigay kalutasan sa mga problema at pagdedesisyon." 3 Binigyang diin ni D' Andrade na may ibatibang uri ang mga iskemang ito: mga iskemang ukol sa pangyayari, oryentasyon, naratibo, proposisyon, metapora, at imahe. ${ }^{4}$

May iilang mga kognitibong antropolohista na ayaw kilalanin ang pagkakaiba ng iskemang pangkognitibo at ng modelong kultural dahil sa katunayan napakaliit naman talaga, at halos hindi na mapapansin, ang kanilang pagkakaiba sa isat-isa. Binanggit nina Naomi Quinn at Claudia Strauss, sa kanilang sanaysay na "Research on Shared Task Solutions," na "ang ibang tawag para sa kultural na iskema (lalo na iyong mga mas komplikadong uri) ay modelong kultural." ${ }^{5}$ Kung tutuusin matatagpuan ang pagkakaiba ng dalawang konseptong ito sa antas ng kanilang pagkakakomplikado (complexity). "Ang

2 Roy D'Andrade, The Development of Cognitive Anthropology (Cambridge: Cambridge University Press, 1995), 1. [Sariling salin]

${ }^{3}$ Gary Palmer, Toward a Theory of Cultural Linguistics (Austin: University of Texas Press, 1996), 63-64. [Sariling salin]

${ }^{4}$ D'Andrade, op cit., 132.

${ }^{5}$ Naomi Quinn and Claudia Strauss, "Research on Shared Task Solutions," in $A$ Cognitive Theory of Cultural Meaning (Cambridge: Cambridge University Press, 1997), 137-188. [Sariling salin] 


\section{0}

MGA MODELO NG PAMUMUNO SA PILIPINAS

mga modelo ay hindi mga iskema," ipinaliwanag ni D'Andrade, "kung ang kolektibo ng kanilang mga elemento ay napakalaki na para mahawakan ng alaalang "short-term" (bilang depinisyon, ang iskema bilang isang may hangganan, malinaw at nag-iisang representasyon, ay dapat kakasya sa alaalang short-term)." "6

Dahil dito, maaaring dalhin ng pag-susuri ng mga modelong kultural ang papel na ito tungo sa isang mas masusing pagsisipat sa mga mas malalaking sistema ng kognitibong istraktura, tulad ng mga sistemang ideolohikal na hindi hayagang matatagpuan sa kultural na kamalayan. Binanggit nina Tara Robertson at Duke Beasley sa kanilang sanaysay na "Cognitive Anthropology," na ang kultural na modelo ay "kadalasang tumutukoy sa kalipunan ng hindi-malay na asumsyon at pagkakaunawaan na taglay ng isang lipunan o pangkat. Malaki ang papel ng mga kultural na modelo sa pag-uunawa ng mga tao sa mundo at ng kilos ng ibang tao. Maaaring ituring ang mga kultural na modelo bilang mga 'loose interpretive framework.' Pareho silang hayagan at hindi-malay na itinuturo at nakaugat sa kaalamang natutuhan mula sa iba at sa naiipong personal na karanasan ...."7 Idinagdag nila na madalas daladala ng mga modelong ito ang mga emosyonal na koneksyon sa partikular na karanasan na lumilikha ng mga pagpapasya kung ano ang normal, natural, at inaasahan sa isang banda, at kung ano naman ang abnormal, hindi-natural, at hindi inaaasahan sa kabilang banda.

Samantalang inumpisahan naman nina Roger Schank at Robert Ableson ang pag-aaral ng mga script at scenario sa kanilang 1977 na aklat na Scripts, Plans, Goals, and Understanding. Ang script para sa kanila ay isang "predeterminado, esteryotipikong pagkakasunod-sunod ng mga kilos na nagbibigay hugis ng isang kilala nang sitwasyon," at ang tao daw ay may libo-libo nito na maaari niyang pakinabangan sa repliksibo at hindi-malay na paraan sakaling kinakailangan ng mga kirkumstansya, ayon kay Palmer.

Magkahalintulad ang script at ang iskemang kognitibo at pareho silang mistulang mga recipe kung paano dapat gagalaw ang tao sa harap ng partikular na sitwasyon. Sinabi ni Gary Palmer, sa kanyang librong Toward a Theory of Cultural Linguistics, na "ang script ay maaaring isang kanta, dasal, hapunan, kasalan, manwal ng teknika, isang robbery-murder, o kahit anong balangkas kung saan ang pagkakasunod-sunod ng mga ideya ay malinaw na nakalatag."

Ang pagkakaiba ng iskemang pangkognitibo at modelong kultural sa isang banda, at ng script at scenario sa kabilang banda, ay matatagpuan lamang sa katotohanang ang nauna ay nasa larangan ng pag-iisip, habang ang nahuli ay nasa larangan ng kilos. Ibig sabihin, ang iskemang pangkognitibo at modelong kultural ay nakatuon sa pag-uunawa, pag-iisip, at pag-aalam; habang ang script at scenario ay nakatuon sa aksyon at paggawa.

Gamit ang mga konsepto ng iskema, modelong kultural, script at scenario, tatangkain ng papel na ito na ipaliwanag na kung kaya hindi gumagana

\footnotetext{
${ }^{6}$ D'Andrade, op cit., 151-152.

7 Tara Robertson and Duke Beasley, "Cognitve Anthropology," in Anthropological

Theories: a Guide Prepared by Students for Students Web Page < http://www.as.ua.edu/ant/Faculty/murphy/436/coganth.htm>, 24 September 2002.

${ }^{8}$ Palmer, op cit.
} 
nang maayos ang demoktratikong pulitikal na sistema sa Pilipinas dahil hindi tumutugma ang modelo ng pamumuno na kinakailangan ng demokrasya at ang modelo ng pamumuno na karaniwang matatagpuan natin sa ating kultura at namana natin mula sa ating kasaysayan. Kagaya ng sinabi ni Jose Abueva, sa kanyang sanaysay na Filipino Democracy and the American Legacy, na ang demokrasya, "ay may kanyang sariling pre-suposisyon, kondisyon, at mga instrumento ... na hindi dapat nating isipin bilang kapareho sa nilalaman ng demokrasya na walang iba kung hindi ang partisipasyon ng mga tao sa pagdedesisyon na nakaka-apekto sa lahat," maaaring nangyari nga na noong ipinataw ng mga Amerikano sa atin ang demokratikong sistema ng pulitika, hindi angkop ang kamalayan ng mga Pilipino noon sa mga hinihiling ng bago at kanluraning sistemang ito, at maaaring ang hindi pagkaka-angkop na ito ay namana natin at patuloy na umiiral hanggang sa kasalukuyan. ${ }^{9}$

Kung gayon, may limang layunin ang papel na ito. Una, tatalakayin nito ang modelo ng pamumuno na hinihiling ng demokratikong sistema, kasama na ang mga naaangkop nitong iskema, script at scenario na dapat nasa isipan at isinasagawa ng mga mamayan. Gagamitin dito ang kaisipan ni Max Weber na isa sa mga nangungunang teorisistang nagdalumat tungkol sa modernong demokrasya at pamumuno. Pangalawa, tatalakayin ng papel na ito ang mga modelo ng pamumuno na nagmumula sa ating kasaysayan bilang mga Pilipino, kasama din ang mga naaangkop nilang iskema, script at scenario na dapat nasa isipan at isinasagawa ng mga sinaunang Pilipino. Gagamitin naman dito ang pananaliksik ng historyador na si Zeus Salazar. Pangatlo, ipapakita ng papel na ito kung paano sinira, pinatawid sa panahon, at binago nang bahagya ang mga sinaunang modelo ng pamumuno ng mga Pilipino. Pang-apat, ilalahad ng papel na ito ang hindi pagkakatugma ng modelo ng pamumuno na hinihiling ng demokrasya at ng ating kaisa-isang modelo ng liderato na matagumpay na nakatawid mula sa ating kasaysayan hanggang sa kasalukuyan. Panglima at panghuli, tatangkain ng papel na ito na magmungkahi ng ilang posibleng mga bagay na maaari nating gagawin bilang tugon sa ugat ng ating problema sa demokratikong pamumuno.

\section{Ang Modelo ng Pamumuno sa Demokratikong Sistema Ayon kay Max Weber}

Si Max Weber (1864-1920), isang Alemang ekonomista, dalubhasa sa agham pulitika at sosyolohista, ay ipinanganak sa Erfurt, nag-aral ng abogasya sa mga unibersidad ng Heidelberg, Berlin, at Gottingen, at naging propesor ng ekonomiya sa mga unibersidad ng Freiburg, Heidelberg at Munich. Dahil sa kanyang humihinang kalusugan, isinantabi niya ang kanyang karera sa akademya at inialay ang kanyang panahon bilang patnugot sa isang Aleman na journal tungkol sa sosyolohiya, ang Archiv für Sozialwissenschaft und Sozialpolitik. Si Weber ay hindi lamang kilala dahil sa kanyang teorya tungkol sa pag-unlad ng

9 Jose Veloso Abueva, "Filipino Democracy and the American Legacy," in Annals of the American Academy of Political and Social Science, 428 (November 1976), 114-133. [Sariling salin] 


\section{MGA MODELO NG PAMUMUNO SA PILIPINAS}

kanluraning kabihasnan, o sa kanyang pagbatikos sa Marxistang teorya tungkol sa materyalistang determinismo, siya ay kilala din dahil sa kanyang klasikong pag-aaral sa istraktura ng demokrasya at pati na sa kanyang pagdadalumat sa mga modelo ng pamumuno.

Ginamit ni Weber ang Alemang salita na "Herrschaft" na may hindi tiyak na katumbas sa Ingles, sa Espanyol, at pati na sa Filipino. Isinasalin ng mga eksperto sa pilosopiya ni Weber ang salitang ito bilang "dominasyon," "pagmamando," "pamamahala," "awtoridad," at "liderato."10 Sa sanaysay na ito, tutumbasan natin ang salitang "Herrschaft" ng salitang "pamumuno." Matapos niyang saliksikin ang mga paraan ng pamumuno sa kasaysayan ng kanluran at silangan, dinalumat ni Weber ang tatlong purong modelo ng pamumuno: ang tradisyunal, karismatiko, at legal-burukratikong mga pamumuno. ${ }^{11}$

Ang tradisyunal na modelo ng pamumuno, na matatagpuan natin sa mga patriyarka, hari, prinsipe, at pyudal na ginoo, ay isang uri ng pamumuno na kumukuha ng kanyang kapangyarihan mula sa nakaraan, o ang tinatawag ni Weber na "walang hangganang kahapon", o "eternal yesterday."12 Dahil nakalatag ang ganitong pamumuno sa mahabang panahon, ito ay isinasalin at ipinamamana mula sa ama patungo sa anak. Malinaw para kay Weber na ang tradisyunal na modelo ng pamumuno ay hindi naaangkop sa isang demokratikong sistema, dahil sa modelong ito hindi maaaring magkakaroon ang mga mamamayan ng karapatang pumili ng kanilang pulitikal na pinuno, at dahil walang lantaran at malinaw na pananagutan ang pinuno sa mga mamamayan.

Ang karismatikong modelo ng pamumuno, na matatagpuan natin sa mga propeta, sa mga piling mandirigma, at sa karamihan ng mga halal na pulitiko, ay isang uri ng pamumuno na kumukuha ng kapangyarihan mula sa hindi pangkaraniwang katangian ng isang tao, na naging dahilan kung bakit tinitingala, sinusunod, at sinusuportahan siya ng mga mamamayan. Karisma ang tawag ni Weber sa hindi pangkaraniwang katangian, o mga katangiang, ito, at ang karisma ay isang bagay na hindi namamana. Sinabi ni Weber: "may pamumuno din na nakabatay sa personal na biyayang grasya (karisma), lubusang personal na debosyon at personal na tiwala sa rebelasyon, heroismo o sa ibang katangiang sa pamumuno ng isang indibidwal."13 Sina Julius Ceasar, Hesu Kristo, Mahatma Gandhi, Adolf Hitler ang ilan sa mga halimbawa ng isang karismatikong pinuno.

Ang mga dakilang karismatikong pinuno ay kadalasan umuusbong sa panahon ng krisis. Ipinaliwanag ni Peter Breiner, sa kanyang librong Max

${ }^{10}$ See Peter Lassman, "The Rule of Man over Man: Politics, Power and Legitimation," in The Cambridge Companion to Weber, ed. By Stephen Turner (Cambridge: Cambridge University Press, 2000), 86.

11 See Max Weber, "The Profession and Vocation of Politics," in Weber: Political Writings, ed. by Peter Lassman and Ronald Spiers (Cambridge: Cambridge University Press, 1994), 311.

12 See ibid.

${ }^{13}$ Ibid. [Sariling salin] 
Weber and Democratic Politics na, "Hindi katulad sa tradisyunal at legalburukratikong pamumuno, ang karisma ay isang uri ng pamumuno na tumatakwil sa pang-araw-araw at pa-ulit-ulit na pagsunod. Nilalayon nito na rumesponde sa mga kahilingan at pangangailangang hindi kayang tugunan ng pang-araw-araw na ekonomiya, o hindi kaya isinasantabi lamang."14 Samantalang ang mga karaniwang karismatikong pinuno sa demokratikong pulitikal na sistema ay hinuhubog mula sa mga maliliit na mga pangkat at organisasyon sa loob ng isang lipunan, at nakikilala ng mas maraming mamamayan habang sila ay sumasabak sa ibat-ibang pulitikal na gawain.

Ang legal-burukratikong modelo ng pamumuno naman, na matatagpuan natin sa mga pinuno ng maraming pampublikong tanggapan at pribadong sektor ay isang uri ng pamumuno na kumukuha ng kapangyarihan mula sa nakasulat na organisasyon at istraktura ng pamahalaan o kompanya. Ang kapangyarihan nito ay hindi namamana o nakabatay sa hindi pangkaraniwang katangian ng sinuman. Ang isang tao ay nagiging isang legalburukratikong pinuno dahil sa kanyang kuwalipikasyon at promosyon na sumasang-ayon sa nakasulat na organisasyon at istraktura ng kanyang tanggapan. Sinabi ni Weber: "nandiyan din ang pamumuno na nakabatay sa bisa ng 'legalidad,' sa bisa ng isang nakasulat na batas at ng bisa ng kakayahan na nakabatay naman sa mga alituntuning rasyunal na nilikha."15 Ang isang legal-burukratikong pinuno ay isang tipo ng tao na ginagampanan niya nang napakahusay ang kanyang mga obligasyon. Kaya lang, ang ginagawa niya ay ang mga bagay lamang na nakasaad sa kanyang job description, walang labis at walang kulang. Dahil tahimik na ginagawa ng mga pinunong ito ang kanilang mga tungkulin, madalas hindi sila naaalala sa kasaysayan tulad ng pagkaka-alala natin sa mga karismatikong pinuno.

Ang pagteteorya ni Weber tungkol sa demokrasya ay nakatuon sa isang partikular na anyo ng demokrasya na laganap ngayon sa buong mundo lalo na sa mga malalaking estado, ang "Führerdemokratie," o "leader democracy." Ang anyo ng pulitikal na sistemang ito ay naiiba sa sinaunang Griyegong demokrasya, o sa mga demokrasya ng mga maliliit na estado, kung saan inaaasahan ang direktang pulitikal na partisipasyon ng mga mamamayan. Sa halip, sa sistema ng leader democracy, ang pang-araw-araw na gawaing pulitikal ay ipinaubaya na ng mga mamamayan sa kanilang hinalal na mga pinuno. Sa katunayan, naniniwala si Weber na imposible nang mabalikan pa ng mga malalaking estado at modernong estado ang sinaunang demokratikong mithiin tungkol sa malawakan, masinsinan at tunay na partisipasyong pulitikal ng bawat mamamayan. Ito ay dahil para sa malalaking estado, mahirap kahit isipin man lamang na makikialam pa ang napakaraming mamamayan sa aktwal na pamamahala; at para naman sa mga maliliit na modernong estado, hindi rin maaaring tutukan nang husto ng mga mamamayan ang pulitika sa puntong maisasantabi na nila ang kani-kanilang mga pang-ekonomikong gawain. Sa

14 Peter Breiner, Max Weber and Democratic Politics (Ithaca: Cornell University Press, 1996), 139. [Sariling salin]

15 Weber, "The Profession and Vocation of Politics," 311. 


\section{MGA MODELO NG PAMUMUNO SA PILIPINAS}

isipan ni Weber, walang ibang alternatibo ang modernong demokrasya kung hindi tahakin ang landas ng leader democracy.

Ayon kay Weber, sa sistema ng leader democracy, ang mga pinuno ay kadalasan mga karismatikong tao, na dahil sa kanilang karisma ay inihalal ng mga mamamayan. Ang karismang ito ay makikita sa kanilang mga makabagbag-damdaming talumpati, mga hindi pangkaraniwang kilos at galaw, at mga magagandang pangarap para sa lipunan. Ngunit, dahil nakabatay ang pamumunong ito sa personal na karisma ng iilang tao, ang karismatikong modelo ng pamumuno ay isang hindi matatag na modelo. Ang karisma ng isang tao kasi ay maaaring maglaho sa paglipas ng panahon, tulad ng nangyari kay Hitler, o maaaring masapawan ng mas makapangyarihang karisma ng isa pang umuusbong na pinuno, tulad ng kadalasang nangyayari sa labanan ng mga pulitiko. Bukod pa nito, ang kapangyarihan na nakalagay sa iilang kamay lamang ay madaling naabuso. Kaya para kay Weber, ang karismatikong modelo ng pamumuno ay hindi sapat para sa isang leader democracy.

Para maging mas matatag ang pamumuno ng isang demokratikong lipunan, at para maiiwasan ang pagiging isang diktador ng isang karismatikong pinuno, iminungkahi ni Weber na ang karismatikong pamumuno ay tatapatan ng isang matatag na legal-burukratikong sistema. Isinulat niya: "taliwas sa anumang uri ng burukratikong organisasyon at tanggapan, ang karismatikong istraktura ay walang paki-alam sa hugis o sa nakahanay na proseso sa pagpili or pagtanggal ng mga opisyal. Wala itong paki-alam sa isang isinaayos na karera, promosyon, sahod, o sa isinaayos na ekspertong pagsasanay sa mga may hawak ng karisma o sa kanyang mga katuwang." 16 Sa madaling pagkasabi, ang legalburukratikong sistema ay siyang magbibigay ng istraktura sa demokratikong pamahalaan, at pipigil sa karismatikong pinuno para hindi ito mang-abuso at umastang diktador.

Sa kabilang banda naman, ang karismatikong pinuno ay siyang magbibigay ng lehitimasyon sa demokratikong pamahalaan at magtutulak sa buong organisasyon tungo sa kaunlaran at mga pagbabago dahil ang burukrasya ay may likas na pagka-estatiko. Binigyang diin ni Weber na: "Kapag naitatag na, ang burukrasya ay isa sa mga panlipunang istraktura na pinakamahirap buwagin."17 Kung transaksyunal ang likas ng burukrasya, transpormatibo naman ang karismatikong pamumuno. Kaya malinaw na kailangan nila ang isat-isa para sa isang matatag at maunlad na demokrasya. Ngunit, ang ugnayan sa pagitan ng karismatikong pinuno at ng burukrasya ay isang ugnayan ng pagmamatyag at kooperasyon, at hindi isang ugnayan ng kolaborasyon at pagtatakipan sa anumang pagkakamali.

Sa puntong ito mararamdaman na natin ang pagkukulang ng modelo ng pamumuno na umiiral sa ating sariling demokratikong sistema ng pulitika. Ngunit, hayaan ninyo ang papel na ito na saliksikin pa ang historikal na pagusbong ng ating lokal na modelo ng pamumuno.

16 Max Weber, "The Sociology of Charismatic Authority," in Max Weber on Charisma and Institution Building, ed. by S. N. Eisenstadt (Chicago: University of Chicago Press, 1968), 1920.

${ }^{17}$ Max Weber, "Bureaucracy," in ibid., 75. 


\section{Ang mga Modelo ng Pamumuno ng mga Sinaunang Pilipino}

Si Zeus Salazar (1934), isang Pilipinong historyador at dalubhasa sa kulturang Pilipino, ay nag-aral ng kasaysayan sa Unibersidad ng Pilipinas, at ng etnolohiya sa Unibersidad ng Paris IV, Sorbonne, nagkaroon ng mga espesyal na pagsasanay sa Ecole Nationale de Langues Orientales Vivantes, sa Paris, sa Freie Universität Berlin, at sa Universiteit te Leiden, at naging propesor ng kasaysayan sa Unibersidad ng Pilipinas. Bukod sa kanyang teoretikal na kontribusyon sa pagbuo ng post-kolonyal na diskurso na tinatawag bilang "pantayong pananaw," kilala din si Salazar sa kanyang pananaliksik tungkol sa pamumuno sa loob ng mga lipunang Pilipino noong panahon bago pa man dumating ang mga mananakop na Espanyol.

Ayon kay Salazar, noong unang panahon tayong mga Pilipino ay mayroong apat na mga modelo ng pamumuno: ang pamumuno ng datu, ng bagani, ng babaylan at ng panday. Binanggit niya na "ang datu ang siyang responsable sa pamamahalang pulitikal, sa tungkuling militar at pati sa kabuuan ng ekonomiya ng baranggay-i.e., komersyo at agrikultura."18 Iniiwasang ituring ni Salazar ang datu bilang ating sinaunang pinunong pulitikal, dahil ang tungkuling ito ay inilalaan niya sa mga "tunay na pinunong pulitikal na maaaring tawaging hari, lakan, radya, o pagkatapos, kahit sultan" na silang namumuno sa iilang pinagsama-samang baranggay. ${ }^{19}$ Ibig niyang sabihin, ang datu ay siya ngang pinakamataas na pinuno sa loob ng barangay, ngunit kapag ang higit sa isang baranggay ay nagsama-sama sa ilalim ng isang pamumuno, ang pinakamalakas at pinakamahusay na datu nila ay siyang itinuturing na hari, lakan, radya o kaya sultan. ${ }^{20}$ Gayunpaman, malinaw na sa loob ng baranggay, ang datu ay siya ring pultikal na pinuno na halos walang pinagkakaiba sa isang patriyarka.

Kapag titingnan natin sa perspektibo ng tatlong modelo ng pamumuno ni Weber, magmimistula ang pamumuno ng datu na pinaghalong karismatiko at tradisyunal na mga pamumuno; dahil nakakuha ang ibang datu ng kapangyarihan mula sa kani-kanilang hindi pangkaraniwang karisma, tulad ng tapang at husay sa larangan ng pakikidigma; habang nakakuha naman ng kapangyarihan ang iba mula sa pamana ng kani-kanilang ama at ninuno. ${ }^{21}$ Iilan sina Lapu-lapu, Humabon, Sulayman, Matanda, at Lakandula sa mga pinakakilalang mga datu dahil napasama sila sa kasaysayang isunulat ng mga Espanyol.

Ang bagani, o bayani, ay isang pinuno ng baranggay na kumukuha ng kanyang kapangyarihan sa kanyang lakas, tapang at paninindigang ipaglaban ang kanyang lipunan sa anumang eksternal na banta. Ipinaliwanag ni Salazar na: "Magkaugnay ang batayang datu at ang bayani dahil sa ang bayani ay ang

18 Zeus Salazar, Ang Babaylan sa Kasaysayan ng Pilipinas, in Bagong Kasaysayan: Mga Pagaaral sa Kasaysayan ng Pilipinas (Quezon City: Palimbagan ng Lahi, 1995), 4.

${ }^{19}$ Ibid., 5.

${ }^{20}$ See Zeus Salazar, Kasaysayan ng Kapilipinuhan: Bagong Balangkas (Quezon City: Bagong Kasaysayan, 2004), 12-13.

${ }^{21}$ See Ibid. 


\section{MGA MODELO NG PAMUMUNO SA PILIPINAS}

naituturing na tagapagtanggol sa balangay laban sa karahasan, kaya kung hindi ang datu mismo ang nagiging bayani ng balangay ay mayroon siyang iilang bayani na inaatasan bilang tagapagtanggol ng baranggay." 22 Madalas nakabatay ang katayuan ng isang bagani sa bilang ng kanyang kalabang napaslang. Ayon sa ating mga linggwista, ang salitang 'bayanihan', ay nangangahulugang pagkilos na parang mga bagani, na walang ibig sabihin kung hindi ang pagsisilbi sa kapakanan ng baranggay sa panahon ng kapayapaan. Gayunpaman kahit tinitingala ang bagani sa loob ng baranggay, wala siyang tunay na pulitikal na kapangyarihan.

Kapag titingnan natin sa perspektibo ng tatlong modelo ng pamumuno ni Weber, malinaw na lalabas ang pamumuno ng bagani bilang isang karismatikong pamumuno; dahil walang ibang pinagbabatayan ang kanyang pamumuno maliban sa kanyang personal na lakas, tapang at paninindigan. Dahil malaking pangkat ang mga bagani, wala tayo masyadong nakikilalang indibidwal na mga bagani.

Ang babaylan ay isang pinuno ng baranggay na humuhugot ng kapangyarihan sa kanyang kalaaman tungkol sa mga espiritwal at praktikal na bagay. Isinulat ni Salazar: "Sa astronomiya, relihiyon at medisina, ang babaylan ang batayan. Siya ang namamahala sa mga ritwal. Kinakausap din niya ang mga anito upang maitakda ang panahon ng pagtatanim. Siya rin ang namamahala sa pagdiriwang na isinasagawa para sa mga pumanaw na kababayan." 23 Sa mas madaling pagkasabi, ang babaylan ay ang nagsisilbing daluyan ng mga pangkasaysayang alala ng baranggay, tagapaglunsad ng mga ritwal, at tagapamagitan ng baranggay at ng kanilang mga diyos at diyosa. Sa apat nating sinaunang modelo ng pamumuno, tanging ang babaylan lamang ang kontrolado ng mga kababaihan. Sa katunayan, ang iilang mga lalaking gumanap sa tungkulin ng babaylan ay dapat mag-aayos babae tuwing may inilulunsad na mahalagang ritwal.

Kapag titingnan natin sa perspektibo ng tatlong modelo ng pamumuno ni Weber, magmimistula rin ang pamumuno ng babaylan bilang pinaghalong karismatiko at tradisyunal na mga pamumuno. Masasabi nating ito ay tradisyunal na pamumuno dahil siya ay kumukuha ng kanyang kapangyarihan mula sa mga sinaunang babaylan na nagpamana sa kanya ng kaalaman tungkol sa kanilang kultura, pananampalataya at medisina. Sa kabilang banda, masasabi nating siya ay karismatikong lider dahil ang pagpapamana ng kaalaman ng babaylan ay hindi nakabatay sa ugnayan ng magulang at anak. Ipinapamana ang pagiging babaylan batay sa ilang mga palatandaan at potensyal ng mga kabataan. Sina Tamblot ng Bohol at Tapar ng Panay ay ilan sa mga nakikilala nating mga lalaking babaylan sa ating kasaysayan. Kapag susuyurin natin ang mga liblib na probinsya at baranggay matatagpuan pa rin natin ang mga kasalukuyang babaylan.

Ang panday naman ay isang pinuno ng baranggay na humuhugot ng kapangyarihan mula sa kanyang praktikal na kalaaman sa paggawa ng sandata,

$$
\begin{aligned}
& 22 \text { Ibid. } \\
& { }^{23} \text { Ibid. }
\end{aligned}
$$


at kagamitan sa pagsasaka at pamamahay. ${ }^{24}$ Sa Kabisayaan, 'panday' pa rin ang ginagamit na salita para sa panday at anluwagi, o karpentero, ng mga Tagalog, ngunit ang panday na tinutukoy ni Salazar ay iyong mga manlilikhang gumagamit ng ibat-ibang klaseng metal bilang pangunahing materyal.

Kapag titingnan natin sa perspektibo ng tatlong modelo ng pamumuno ni Weber, mahirap uriin ang pamumuno ng panday; dahil hindi ito lubusang naangkop sa alinman sa tatlong modelo ni Weber. Pinakamalapit na siguro ang panday sa modelo ng karismatikong pamumuno, sa puntong ang kanyang praktikal na talento ay maaaring ituring bilang isang karisma. Isa sa mga pinakakilalang panday sa ating kasaysayan ay si Panday Pira, ang Morong tagagawa ng sandata ni Radja Sulayman na kalaunan ay inanyayahan ng mga Espanyol na maging tagagawa nila ng kanyon.

Sa puntong ito naungkat natin, sa tulong ng pananaliksik ni Salazar, ang kaalaman na ang mga sinaunang Pilipino ay may apat na modelo ng pamumuno. Una, ang pamumuno ng datu na umiiral sa larangan ng pulitika at ekonomiya, at kahalintulad sa pinagsamang karismatiko at tradisyunal na pamumuno ni Weber. Pangalawa, ang pamumuno ng bagani na umiiral sa larangan ng pagpapanatili ng kapayapaan at serbisyo publiko, at kahalintulad ng karismatikong pamumuno ni Weber. Pangatlo, ang pamumuno ng babaylan na umiiral sa larangan ng kultura at espiritwalidad, at kahalintulad sa karismatikong pamumuno ni Weber. Pang-apat, ang pamumuno ng panday na umiiral sa larangan ng teknolohiya, at may pagkakahawig sa karismatikong pamumuno ni Weber.

Iba-iba ang kinasasapitan ng apat na sinaunang modelong ito nang dumating ang mga mananakop na Espanyol na sinundan naman ng mga Amerikano na parehong may kani-kanilang pamamaraan sa pagbago sa istraktura at anyo ng lipunang Pilipino. Tuluyang sinira ng mga Espanyol ang bagani, ang babaylan at ang panday, sa puntong hindi na nakatawid ang mga ito bilang mga modelo ng pamumuno sa panahon ng mga Amerikano. Naiiba ang nangyari sa datu, dahil ginamit ito pareho ng mga Espanyol at Amerikano bilang katuwang sa kanilang kolonyal na gawain. Kaya sa sumusunod na mga seksyon ng papel na ito, tatalakayin nang hiwalay ang mga detalye tungkol sa pagkasira ng mga modelo ng bagani, babaylan at panday sa isang banda, at sa pananatili at transpormasyon ng modelo ng datu sa kabilang banda.

\section{Ang Paglaho ng Babaylan, Bagani, at Panday Bilang mga Modelo ng Pamumuno sa Pagdating ng mga Espanyol}

Bago natin tingnan ang kinasasapitan ng bagani, babaylan at panday, alalahanin natin na ang matagumpay na pananakop ng mga Espanyol ay nakabatay sa kanilang mas makapangyarihang pulitikal, militar/pampulisya, kultural at relihiyosong mga makinarya. Kaya ang mga modelo ng pamumuno na istraktural na sumalungat sa alinman sa mga makinaryang ito ay tiyak na mawawalan ng puwang sa kolonyal na lipunan.

${ }^{24}$ See Ibid. 


\section{MGA MODELO NG PAMUMUNO SA PILIPINAS}

Matingkad na matingkad ang istraktural na pagkakasalungat ng pamumuno ng bagani at ng militar/pampulisyang makinarya ng mga Espanyol, kaya unang-unang nawalan ng puwang ang bagani. Ang pagkasakop ng baranggay sa kolonyal na kapangyarihan ay nangangahulugan ng pagsuko nito ng kanyang karapatang bantayan ang kanyang kapayapaan. Ibig sabihin ang tungkulin sa pagpapanatili ng kapayapaan sa loob ng baranggay na dati rati ay pangunahing tungkulin ng bagani, ay inangkin na ng militar/pampulisyang makinarya ng mga Espanyol.

Malaki ang posibilidad na ang mga kabataang may potensyal sanang maging bagani sa lumang kaayusan ay sumanib na lamang sa militar/pampulisyang makinaryang kolonyal bilang mga kasapi ng mga bantayanes, comisarios del tribunal, cuerpo de cuadrilleros, o hindi kaya sa mga mas nahuhuling lupon ng tercios de policia, carabineros de seguridad publica, at guardia civil. $^{25}$ Alalahanin natin na dahil sa kakulangan ng tauhan napilitan ang mga Espanyol na tumanggap ng mga katutubo para maging kasabwat nila sa pagpapatakbo ng kanilang militar/pampulisyang makinarya. Gayunpaman, ibang-iba ang katayuan at dangal ng bagani sa katayuan at dangal ng sinumang kasapi sa alinman sa mga hukbong ito, dahil ang kani-kanilang matataas na puwesto ay nakalaan lamang sa mga Espanyol. Kaya malinaw na sinira ng kolonyal na rehimen ang modelo ng pamumuno ng bagani. Malaki din ang posibilidad na ang ibang kabataang may potensyal ding maging bagani sa lumang kaayusan na ayaw sumanib sa mga hukbong kolonyal ay napasama sa mga lupon na binansagang "bandidos," "ladrones," "tulisanes" at "remontados" ng mga Espanyol.

Matingkad na matingkad din ang istraktural na pagkakasalungat ng pamumuno ng babaylan at ng kultural at relihiyosong makinaryang kolonyal, kaya nawalan din ng puwang ang babaylan. Ang pinakamahigpit na kalaban ng babaylan ay ang prayleng Espanyol dahil sa pagkakahawig ng kanilang kultural at espiritwal na mga gawain. Ngunit hindi katulad sa mga natitirang bagani at mga kabataang may potensyal sanang maging bagani sa lumang kaayusan, ang mga babaylan ay hinding-hindi maaaring makihalo sa larangang sapilitang inagaw ng mga prayle. Babae ang karamihan sa mga babaylan, habang lalaki ang lahat ng mga prayle; katutubo ang mga babaylan, habang Espanyol ang mga prayle; animistiko at masalimuot ang teolohiya ng mga babaylan, habang monoteistiko at tekstwalisado ang teolohiya ng mga prayle. Dagdag pa nito, ang mga mananakop na Espanyol ay may dala-dala ding prestihiyosong propesyunal na manggagamot, ang kanilang doktor sa medisina, na sumalungat sa gawaing pangkalusugan ng mga babaylan. Kaya ang mga babaylan ay naisantabi mula sa sentro ng barangay at naging mga alternatibong manggagamot na lamang na kilala bilang mga kuranderos at arbolaryo.

Kung istraktural na sumalungat ang mga pamumuno ng bagani at babaylan sa militar, kultural at relihiyosong mga makinarya ng kolonyal na kaayusan, tila walang sinalungat na makinarya ang pamumuno ng panday. Sa

25 See Greg Bankoff, Crime, Society and the State in the Nineteenth-Century Philippines (Quezon City: Ateneo de Manila University Press, 1996), 129-138. 
katunayan, naging mahalagang katuwang pa nga ang panday sa kolonyal na kapangyarihan bilang patuloy na tagalikha ng mga kagamitan at sandata, katulad sa nangyari kay Panday Pira. Gayunpaman, pagdating nang bagong kaayusan nasira pa rin ang pagiging modelo ng pamumuno ng panday. Marahil bunsod ito sa katotohanang sa Europyanong balangkas ng mga Espanyol, ang panday ay isang hamak na manggagawa lamang. Marahil din na bunsod ito sa pagkalusaw sa dating monopoliya ng panday sa paglilikha ng mga gamitan at sandata nang dumagsa sa ating bansa ang mga banyagang kagamitan at sandata mula sa Mehiko at Espanya.

Dahil sa mga pangyayaring ito tuluyan nang nasira ang bagani, babaylan at panday bilang mga modelo ng pamumuno at hindi na sila nakatawid pa sa panahon ng mga Amerikano. Kaya sa kasalukuyan wala na tayong makikitang mga bagani. Samantalang ang iilang mga babaylan at panday na patuloy nating matatagpuan sa mga liblib na sulok ng ating bansa ay mga taong marhinalisado na, na kapag pagmamasdan natin ay mahihirapan tayong mag-isip na noong unang panahon sila nga ay mga mahahalagang pinuno ng lipunan.

Nakapanghihinayang lalong-lalo na ang nangyari sa bagani sa dahilang ito sana ang isang napakahusay na batayan at halimbawa hindi lamang para sa ating mga kasalukuyang lider, kung hindi pati na rin sa ating mga mamamayan. Dahil ang mga bagani ay isang pangkat ng mga mamamayan na ang tanging tunguhin sa buhay ay pagsilbihan ang baranggay. Napakamatagumpay ang pagkakabura nila ng mga Espanyol sa puntong karamihan sa atin ngayon ay wala nang kamalayan tungkol sa kanila, at para sa atin ang salitang 'bagani', o 'bayani', ay napalitan na ng kahulugan bilang "beroe" sa Espanyol, o "bero" sa Ingles. Ang heroe, o hero, ay kailangang gumanap ng isahang napakadakilang gawain, na madalas ay maaari niyang ikamatay para sa bayan; habang ang bagani ay tuloy-tuloy sa kanyang pagganap ng mga gawain, maliit man o malaki, para sa kanyang bayan. Kaya mas madali para sa mas maraming Pilipino ang magpakabayani, kaysa magpaka"hero."

\section{Ang Transpormasyon ng Datu Bilang Modelo ng Pamumuno sa Ilalim ng Kolonyal na Pananakop ng mga Espanyol at Amerikano}

Sa apat na sinauna nating modelo ng pamumuno, tanging ang sa datu lamang ang hindi naglaho sa ilalim ng kolonyal na kaayusang Espanyol. Sinabi ni Dante Simbulan, sa kanyang librong The Modern Principalia: the Historical Evolution of the Philippine Ruling Oligarchy, "Ang mga datu ay nakatakdang hindi mawalan ng kanilang tungkulin sa pamumuno, kapag ang kanilang ugnayan sa kani-kanilang mga tao ang pinag-uusapan. Dahil sa kakapusan ng mga tauhan para ipairal ang kanilang kapangyarihan sa kapuluan, nagpasya ang mga Espanyol na gamitin ang mga katutubong kasapi sa mataas na uri para maging 


\section{0}

MGA MODELO NG PAMUMUNO SA PILIPINAS

katuwang ng sentral na pamahalaan sa pagpapatakbo ng mga baranggay."26 Sa katunayan, batay sa payo ng mga Agustinong prayle, binigyan sila ni Haring Felipe II ng mga pribilehiyo. "Ang mga datu at ang kani-kanilang panganay na anak," ipinaliwanag ni Simbulan, "ay binawasan ng obligasyong magbayad ng taunang tributo at sumali sa sapilitang paggawa (forced labor)." 27 Sa mga panahong ito kinilala ang mga datu bilang mga cabeza de baranggay, o mga ulo, o pangulo ng baranggay, na ang pangunahing tungkulin ay ang pagkolekta ng buwis mula sa kanyang mga sakop.

Kahit patuloy na namamayagpag ang modelo ng pamumuno ng datu sa ilalim ng kolonyal na kaayusang Espanyol, nakadanas ito ng maraming pagbabago at transpormasyon sa kanyang istraktura at anyo. Ayon kina Simbulan at Abueva hindi kukulang sa lima ang pinakamahalaga sa mga ito. Unang-una dito ay ang kanyang pundasyunal na transpormasyon na bunsod sa pakikipagsabwatan ng datu sa kolonyal na kapangyarihan. Binigyang diin ni Abueva: "kumilos ang mga maliliit na lokal na burukratong ito bilang mga tagapamagitan, nagpapaabot ng kagustuhan ng mga kolonyalista, nagpapatupad ng kanilang kapangyarihan at awtoridad sa mga Pilipino at nagtatakip sa mga kolonyalista laban sa galit ng mga taong-bayan." 28 Kaya sa halip na magiging pinuno ng baranggay at para sa baranggay, nagmistulang galamay na lamang ang pamumuno ng datu/cabeza ng mga mananakop na Espanyol.

Ang ikalawang transpormasyon na dinanas ng modelo ng pamumuno ng datu ay ang kanyang heyograpikal na relokasyon mula sa baranggay patungo sa pueblo noong itinatag ng mga Espanyol ang pulitikal na espasyong ito sa pamamagitan ng redaksyon ng ilang baranggay para magsama-sama sa iisang pook kung saan pumapagitna ang simbahan at ang munisipyo. Ang pueblo ang siyang pisikal na naghihiwalay sa datu/cabeza sa pamayanan ng kanyang mga sakop. Sa perspektibo ng mga ordinaryong mamamayan, unti-unting naging banyaga na ang kanilang sariling datu/cabeza.

Ang ikatlong transpormasyon na dinanas ng pamumuno ng datu ay kaakibat pa rin sa pagtatag ng pueblo na siyang naging lunsaran sa pag-inog ng datu/cabeza at ng kanyang kamag-anakan patungo sa isang panibagong uri na kilala bilang "prinsipalya." Nagbigay ang pueblo ng pagkakataong makamtan ng datu/cabeza/prinsipalya at ng kanyang kamag-anakan ang dagdag pang kapangyarihang nagmumula sa mga posisyon ng gobernadorcillo, teniente, alguaciles, at iba pang mga empleyado ng pueblo. Kahit sa halalan na-aangkin ang mga pinakamataas sa mga posisyong ito, nananatili sa kamay ng mga datu/cabeza/prinsipalya ang kapangyarihan dahil ang karapatan sa pagboto limitado lamang para sa labingdalawang pinakamataas na cabeza. Kaya inihayag ni Simbulan: "Ito ang bumubuo ng uri ng mga prinsipalya: ang mga heriditaryong cabeza at ang buong lupon ng mga 'halal' na mga pinuno. Sa loob ng mahigit tatlong daang taong paghahari ng Espanya, ang mga ito ang nagmonopolisa sa mga pampublikong posisyon na bukas sa mga Pilipino. Sila

${ }^{26}$ Dante Simbulan, The Modern Principalia: the Historical Evolution of the Philippine Ruling

Oligarchy (Quezon City: University of the Philippines Press, 2005), 18. [Sariling salin]

27 Ibid.

${ }^{28}$ Abueva, op cit., 116. 
ang bumubuo sa uring may pribileheyong bumoto sa lipunang Pilipino."29 Hindi lamang pina-igting ng mga Espanyol ang kapangyarihan ng datu, kung hindi binigyan din ito ng mekanismong mapanatili sa kanyang mga kamay, at sa kamay ng kanyang mga kamag-anakan, ang pulitikal na kapangyarihan. Kung noon ay bukas para sa sinumang katangi-tanging karismatikong mamamayan ang pagkakataong maging isang datu, sa panahon ng mananakop na Espanyol tanging ang mga kasapi lamang sa uri ng datu/cabeza/prinsipalya ay may karapatang mamalagi sa kanilang mataas na panlipunang antas.

Ang ika-apat na transpormasyon na dinanas ng modelo ng pamumuno ng datu ay nangyari sa larangan ng kultura. Sa pueblo, unti-unting natutuhan ng datu/cabeza/prinsipalya ang iilang aspeto ng kultura ng mga mananakop na Espanyol, kasabay sa pagtalikod nito sa mga katumbas na aspeto ng katutubong kultura. Pinakamatingkad sa mga aspetong ito ang edukasyon at wikang kanluranin. Kaya ang pisikal na puwang sa pagitan ng datu/cabeza/prinsipalya at ng pamayanan ng kanyang mga sakop na nilikha ng pueblo ay lalo pang pinalalim at pinalawak sa pagkakabuo ng panibagong puwang sa pagitan ng edukado at bihasa sa wikang Espanyol na datu/cabeza/prinsipalya at sa hindiedukado at hindi-bihasa sa wikang Espanyol na mga sakop. Sa perspektibo ng mga ordinaryong mamamayan, lalong naging banyaga na ang kanilang sariling datu/cabeza/prinsipalya.

Ang ikalimang transpormasyon na dinanas ng modelo ng pamumuno ng datu ay nangyari sa kanyang pisikal na anyo. "Ang pagdaloy ng elemento ng pagkamestiso", isinulat ni Simbulan, "na bunsod sa pagkakahalo ng lahi sa pagitan ng mga pinunong Espanyol, sundalo, pari at mayayamang Tsinong mangangalakal sa isang banda at ang mga Pilipina sa kabilang banda, ay lumikha ng mestisong katangian, hindi lamang sa pananaw at kultura, kung hindi pati na sa pisikal na anyo na, hanggang sa mga araw na ito, ay pansin na pansin sa uri ng mga prinsipalya." 30 Dahil dito lubusan nang naging banyaga ang datu/cabeza/prinsipalya sa perspektibo ng ordinaryong mamamayan.

Bago ipinasa ng mga Espanyol ang pananakop ng kapuluan sa mga Amerikano ang mga sumusunod ay ang kinasapitan ng ating mga katutubong modelo ng pamumuno: una, nilusaw ng mga Espanyo ang mga modelo ng pamumuno ng bagani, babaylan at panday sa puntong hindi na nagkaroon ang mga ito ng pagkakataong tumawid sa panahon ng mga Amerikano; pangalawa, pinanatili nga ng mga Espanyol ang modelo ng pamumuno ng datu ngunit dahil sa kanilang manipulasyon at mga hindi sinasadyang proseso na kaakibat sa pagpapairal ng kolonyal na kaayusan napalayo ang datu/cabeza/prinsipalya sa kalooban, pamumuhay at mundo ng kanyang sariling mga sakop; at pangatlo, tila ang dating magkahalong tradisyunal at karismatikong pamumuno ng datu ay naging tradisyunal na lamang dahil sa pagsara ng mga Espanyol sa posibilidad na ang isang katangi-tangi at karismatikong mamamayan ay maaaring mapabilang sa uri ng datu/cabeza/prinsipalya. Malinaw na parehong dinanas

\footnotetext{
${ }^{29}$ Simbulan, op cit., 19-20.

${ }^{30}$ Ibid., 20.
} 


\section{MGA MODELO NG PAMUMUNO SA PILIPINAS}

ng datu/cabeza/prinsipalya ang mga proseso ng konserbasyon at transpormasyon.

Nang napasakamay ng mga mananakop na Amerikano ang kapuluan, at nang ipinataw nila ang kanilang demokratikong sistema ng pamahalaan, patuloy nilang ginamit bilang mga galamay at kolaborador ang mga datu/cabeza/prinsipalya na kanilang nadatnang pinapakinabangan ng mga Espanyol. Sa katunayan noong taong 1901, nang pinalitan ng mga Amerikano ang sistema ng pueblo ng mas modernong sistema ng munisipal na pamahalaan, bahagya lamang nilang pinapalawak ang kwalipikasyon ng mga indibidwal na may karapatang bomoto. Mula sa labingdalawang pinakamataas na cabeza sa ilalim ng sistemang Espanyol, ang kwalipikasyon na pinairal ng mga Amerikano ay sumasaklaw sa: 1) mga Pilipinong humahawak sa posisyong gobernadorcillo, alcalde, teniente, cabeza de baranggay, at konsehal ng munisipyo; 2) mga Pilipinong may pag-aaring bahay o lupa na may halagang hindi bababa sa limang daang piso, o hindi kaya nagbabayad ng taunang buwis na may halagang hindi bababa sa tatlumpung piso; at 3) mga Pilipinong marunong magbasa at magsulat sa Ingles o Espanyol. Ngunit ipinaliwanag ni Simbulan: "Ang mga Amerikanong pinuno, sa pamamagitan ng pagpapatupad ng mga nasabing kwalipikasyon (kahit hindi pa man nila hayagang sinabi), samakatuwid ay naglimita sa prankisa para lamang sa uring prinsipalya. Maliit na pagbabago lamang ito sa sistema ng mga Espanyol. Tatlong hiwalay na grupo ang tila napasama sa kwalipikasyon subalit ang mga ito, kadalasan, ay parehong grupo ng mga tao."31

Kahit noong lumago na ang ating Amerikanong demokrasya at nang itinatag na ang mga partido pulitikal, nanatiling kontrolado pa rin ng mga angkan ng datu/cabeza/prinsipalya ang mga makinaryang ito. Pinatingkad ni Abueva ang dispalinghadong anyo ng ating mga partido pulitikal: "ang mga ito ay partido ng mga pulitiko, hindi partido ng masa. Ang kanilang mga kasapi ay karamihan mga kandidato para sa mga halal na posisyon na nagmumula sa mayayaman, may lupang angkan na galing sa mga prinsipalya, ilustrado, at cacique ng panahon ng mga Espanyol. Ang ibang nagpapanggap na kasapi ng partido ay karamihan mga kamag-anak at mga alyado ng pulitiko na kasama sa ugnayang patron-client."32 Sa halip na maging mekanismong maghahagilap ng mga karismatikong indibidwal at sasala kung sino sa kanila ang karapatdapat maging mga pinuno, ang ating mga partido pulitikal ay nagmimistulang lunsaran lamang ng mga tradisyunal na pinuno mula sa mga angkan ng datu/cabeza/prinsipalya. Kaya sa panahon ng mga mananakop na Amerikano patuloy pa ring namamayagpag sa kapangyarihan ang mga datu/cabeza/prinsipalya.

Hindi natin lubusang masisisi ang mga Espanyol sa kanilang pakikipagsabwatan sa mga datu/cabeza/prinsipalya dahil wala sa kanilang mga layunin ang pagpapalaganap ng demokratikong sistema. Subalit malaking kontradiksyon ang ginawang pakikipagsabwatan ng mga Amerikano sa

\footnotetext{
${ }^{31}$ Ibid., 41.

32 Abueva, op cit., 120-121.
} 
parehong uri dahil ito ay labag sa kanilang hayagang adhikain para sa demokrasya. Ipinaliwanag ni Abueva: "Kinapos ang mga Amerikano sa pilosopiya ng radikal na pagbabago. Sa mga unang taon, binigyang diin ng mga Amerikanong administrador ang edukasyon, pampublikong kalusugan, at pampublikong imprastraktura, habang isinasantabi muna ang pulitika, sa paniniwalang ang pang-ekonomikong katatagan ang mas mahalaga para sa kasarinlan. Naniniwala din sila na ang mga naluklok ng mga elitista ay maaaring buwagin lamang kapag lubusan nang nagkaroon ng edukasyon ang masa." 33 Ngunit tila napako ang mga Amerikano sa kanilang pansamantalang estratehiya, dahil hindi na nila nalampasan ang itinakda nilang lubusang edukasyon ng masa at lalong hindi na sila nakausad patungo sa mas mahalagang gawain sa pagbaklas sa kapangyarihang taglay ng mga angkan ng datu/cabeza/prinsipalya. Ngayon, may mahigit kalahating siglo na ang nakalipas mula noong tuluyang ibinigay ng mga Amerikano ang ating kasarinlan, subalit ang nakatiwangwang pa rin sa ating demokratikong landas ang lubusang edukasyon ng masa at ang pagbubuwag ng kapangyarihan ng mga elitista.

\section{Ang Hindi Pagkakatugma ng mga Modelo ng Pamumuno sa Kasalukuyang Panahon}

Ang modelo ng pamumuno na namana natin sa ating kasaysayan ay ang katutubo nating modelo ng pamumuno ng datu na hinubog muli ng mga puwersa ng kolonyalismo at naging modelo ng pamumuno ng datu/cabeza/prinsipalya. Ang modelong ito ang siyang nakaukit sa ating kamalayan at nagdidikta sa atin na ang isang aktwal na pinuno ay naiiba dapat sa ating mga ordinaryong mga mamamayan: sa pagiging taga pueblo/lunsod, sa halip na kasamahan lamang natin sa araw-araw na pamumuhay; sa pagiging isang kasapi ng isang mayaman at makapangyarihang angkan, sa halip na sa isang karaniwang angkan lamang; sa pagiging edukado/titulado at marunong magsalita ng Ingles/Espanyol, sa halip na may sapat na kabatiran lamang sa mga suliranin at mithiin ng mga karaniwang mamamayan, at sa halip na marunong magsalita ng wikang naiintindihan ng lahat ng mamamayan; at sa pagiging mestiso, sa halip ng pagkakaroon ng pangkaraniwang anyong Pilipino.

Ngunit, ang modelo ng pamumunong ito ay malayong-malayo sa karismatiko at burukratikong mga pinuno na hinihiling ng sistema ng leader democracy ayon kay Weber. Sa halip ng isang karismatikong pinuno ang hinahalal natin, tayo ay napipilitang pumili ng isang pulitiko mula sa isang napakakitid na listahan ng mga kandidato na kung tutuusin ay lahat nagmumula sa angkan ng mga datu/cabeza/prinsipalya. Kung para kay Weber, 'galing' at 'dating' ang pangunahing mga kwalipikasyon ng karismatikong pinuno, para sa atin pera, kapangyarihan at pagiging 'iba' na kung saan, lahat ay nakaugat sa pagiging kasapi sa angkan ng datu/cabeza/prinsipalya, ang tinitingnang pangunahing kwalipikasyon ng ating mga pulitiko. Dahil makitid ang pinagmumulan ng ating mga pinuno, natural lamang na kadalasan makitid din

${ }^{33}$ Ibid., 122. 


\section{MGA MODELO NG PAMUMUNO SA PILIPINAS}

ang kanilang 'galing' at 'dating'. Kahit hindi deretsahang minamana ang ating demokratikong pamumuno, ang pera, kapangyarihan at pagiging iba, na pangunahing kwalipikasyon nito, ay silang minamana ng ating mga umuusbong na pinuno mula sa kanilang angkan. Dahil dito mas tradisyunal ang ating mga pulitiko kaysa karismatiko, at dahil naiiba sila sa nakararaming mamamayan naiiba din ang kanilang mga adhikain at mithiin sa mga adhikain at mithiin ng mga karaniwang Pilipino.

Bukod sa pagiging tradisyunal ng ating mga pinuno, sa halip na karismatiko, ang mas malaking problema ng ating demokratikong pamumuno ay ang kawalan nito ng katuwang na matatag na burukrasya. Kung aalalahanin natin, binigyang diin ni Weber na magkakapit dapat ang mga modelo ng karismatiko at legal-burukratikong pamumuno sa loob ng isang leader democracy. Ngunit sa halip ng isang matatag na burukrasyang pinapatakbo ng mga legalburukratikong pinuno, mayroon tayong marupok na burukrasyang pinapatakbo ng mga sakop ng hinalal na pinuno. Kung itatanong natin kung bakit hindi matatag ang ating sistemang pulitikal at bakit madali tayong maging biktima sa mga pang-aabuso ng ating mga halal na pinuno - ang pinakasimpleng sagot nito ay dahil wala tayong matibay na burukrasyang gumagabay sa ating mga halal na pinuno. Kitang-kita natin kung gaano kababa ang turing ng mga halal nating pinuno sa ating mga legal-burukratikong pinuno na madalas ay nagmimistulang mga utusan lamang.

Ayon kay Weber para magkakaroon tayo ng isang matatag na burukrasya, una, dapat mayroong malinaw na organisasyon at talaan ng mga tungkulin ang mga pinuno at kawani ng isang tanggapan. Sa aspetong ito marahil hindi tayo nagkukulang. Ngunit sa usapin kung ang mga ito ay nasusunod ba, marahil malaki ang ating pagkukulang. Kilala na natin ang ating mga sarili bilang mahusay sa paglatag ng mga batas at plano at napakahina naman sa pagpapatupad sa mga ito. Pangalawa, dapat mayroong malinaw na kwalipikasyon para sa bawat posisyon ng pinuno at kawani. Sa aspetong ito pumapasok ang masamang kapangyarihan ng mga halal na pinuno, dahil kadalasan naglalagay sila ng mga tao kulang sa kwalipikasyon. Pangatlo, dapat mayroong malinaw na batayan para sa promosyon at demosyon. Mahina din tayo sa aspetong ito dahil sa ating pagkabaon sa sistema ng palakasan kung saan ang mga halal na pinuno ay silang nag-aastang mga padrino na nagbibigay ng pabor sa malalapit sa kanila at parusa sa mga nakakalaban nila. Pang-apat, dapat mayroong resonable at malinaw na pasahod. Mahina ulit tayo sa aspetong ito. Dahil sa kababaan ng pasahod ng ating pamahalaan ang karamihan sa ating mga kababayan ay halos itinutulak na ng kakulangan para gumawa ng hindi tama.

Subalit kung itatanong pa natin kung bakit nga ba nagkaganito ang ating burukrasya? Ang mas malalim na sagot nito ay dahil nag-umpisa tayo sa isang marupok na burukrasyang itinayo ng mga mananakop na Espanyol. Sa isang kolonyal na pamahalaan, malinaw na hindi pangunahing layunin ng mga mananakop ang magtatag ng isang mabisang burukrasya, dahil eksploytasyon at hindi serbisyo publiko ang motibo nila. Kung maaalala natin kahit ang napakahalagang gawain ng pangongolekta ng buwis ay pinaubaya noon ng 
kolonyal na pamahalaan sa mga kamay ng mga enkomiendero sa pamamagitan ng prosesong walang pinagkaiba sa isang prangkisa. Kaya hindi tayo dapat magtaka kung bakit isang mahinang burukrasya lamang ang namana natin mula sa kanila. Sa isang demokrasya lamang naging mahalagang-mahalaga ang isang matatag na burukrasya.

Pero bakit noong ipinataw sa atin ang demokrasya ng mga Amerikano hindi pa rin naging matatag ang ating burukrasya? Ang tanong na ito ay sinagot na ni Abueva. Inuna muna ng mga Amerikano na ayusin ang ekonomiya, edukasyon, kalusugan, at imprastraktura, bago nila pinoproblema ang antidemokratikong paghari-harian ng mga datu/cabeza/prinsipalya. Inisip nila na kapag matatag na ang ekonomiya, edukasyon, kalusugan at imprastraktura dito sa kapuluaan, madali na lamang tugunan ang problema sa patuloy na pamamayagpag ng mga elitista at patibayin at patatagin ang burukrasya. Marahil dahil sa Ikalawang Pandaigdigang Digmaan at sa marami pang hindi tiyak na kadahilanan hindi nila lubusang naisaayos ang mga ito at naiwan sa atin ang isang marupok na burukrasyang napakaselan at napakabulnerable sa pangaabuso ng mga kasapi ng angkan ng datu/cabeza/prinsipalya.

\section{Konklusyon}

Sa puntong ito nailahad ng papel na ito na isa sa mga mahalagang dahilan kung bakit ang bansa natin ay may problematikong pulitikal na kaayusan ay ang hindi pagkakatugma ng modelo ng pamumuno na umiiral sa kamalayan ng ating mga mamamayan at ng modelo ng pamumuno na hinihiling ng isang leader democracy. Tradisyunal ang modelo ng pamumunong nandiriyan sa ating kamalayan, habang karismatikong modelo na may katuwang na matatag na legal-burukratikong modelo naman ang kailangan ng isang leader democracy. Sa ganitong sitwasyon, ano naman kaya ang mga bagay na dapat nating gawin para matugunan ang ganitong ugat ng ating suliraning pulitikal?

Bago pa man natin dalumatin ang mga posibleng tugon, alalahanin natin na dalawang dambuhalang problema ang ating kinakaharap: 1) ang kwestiyonable nating modelo ng tradisyunal na pamumuno na dapat palitan ng isang makatotohanang modelo ng karismatikong pamumuno; at 2) ang marupok nating burukrasya na dapat patibayin at patatagin.

Para sa unang dambuhalang problema, tungkol sa kwestiyonable nating modelo ng tradisyunal na pamumuno, mahalaga ang edukasyong pulitikal na mag-aangat at maghuhubog muli sa ating kamalayan, para mamulat tayong lahat sa mga pundasyunal na kahilingan sa demokrasya. Hindi maaaring hayaan na lamang natin ang ating kawalan ng angkop na modelo ng pamumuno, dahil ganito ang nagawang pagkakamali ng mga Amerikano noong ipinataw nila sa atin ang isang demokratikong sistema. Hindi nila ito sinabayan ng masinsinang paghahanda sa ating kamalayan kung paano dapat mag-isip ang mga kasapi ng isang demokrasya. Inakala nilang kusa natin itong matututuhan sa pag-usad ng ating ekonomiya at demokrasya. Ngunit kapansin-pansin na hanggang ngayon hindi nangyayari ang inaasahang bagay na ito. 


\section{MGA MODELO NG PAMUMUNO SA PILIPINAS}

Ang edukasyong pulitikal na kinakailangan natin ay hindi lamang dapat nakabatay sa isang kritikal at radikal na "Political Science 101," dahil alam na natin na maliit na porsiyento lamang ng ating mga kabataan ang may pagkakataong makaapak sa kolehiyo. Tama lamang na rebisahin ang nilalaman at pagkakaturo ng Political Science 101 mula sa kasalukuyan nitong pagtuon sa konstitusyon patungo sa isang mas kritikal at radikal na pagsusuri sa ating mga pulitikal na estraktura, ngunit hindi pa rin ito sapat. Ang edukasyong pulitikal na kinakailangan natin ay dapat na sumaklaw din sa mga mag-aaral ng high school, sa mga sumasampalataya sa ating mga simbahan, at sa mga kumukonsumo ng ating mas midya, literatura at sining. Totoong napakahirap gawin ang muling paghuhubog ng isang kamalayan subalit dapat may maguumpisa sa ganitong gawain. Ang kinaligtaang gawin ng mga Amerikano noon, ay dapat agaran nating gawin ngayon. Hindi pa huli ang pagsasa-ayos ng ating demokrasya. Kapag namumulat na ang karamihan sa ating mga Pilipino na kailangan pala nating palitan ang ating mga tradisyunal na pinuno ng mga karismatikong pinuno na may pananagutan sa bayan, tiyak na magkakaroon tayo ng mas mabisang demokratikong sistema.

Para sa pangalawa nating dambuhalang problema, tungkol sa marupok nating burukrasya, mahalaga pa rin ang isang malawakang edukasyong pulitikal para magkaisa ang lahat ng mamamayan sa paghiling sa ating mga pinuno na isulong ang pagpapatibay at pagpapatatag sa ating burukrasya. Hindi maaaring i-asa lamang natin ang ganitong pagbabago sa ating kasalukuyang mga tradisyunal na pinuno, dahil ang mga taong ito ay nakikinabangnang husto sa karupukan ng ating burukrasya, kaya malinaw na hindi sang-ayon sa kanilang pansariling interes na patatagin ito. Tayong mga mamamayan mismo ang pupuwersa sa ating mga kasalukuyang tradisyunal na pinuno para aksiyunan nila ang ating problematikong burukrasya. Kapag mamumuno na ang mga bagong karismatikong pinuno, tiyak na mas madali silang pakisuyuan na kumpunihin muli ang ating burukrasya para sa ikabubuti ng lahat. Hindi mahirap ang pagpapatibay at pagpapatatag ng isang burukrasya, dahil ginagawa ito ng marami nating mga mamamayan sa larangan ng mga pribadong korporasyon. Ang tumatatag na demokrasya, lumalagong kapitalistang ekonomiya, at umiinog na modernong estado ay mga dagdag na puwersa para sa pagpapatibay at pagpapatatag ng ating burukrasya.

Kapag na-aangkop na ang ating modelo ng pamumuno sa modelo ng pamumuno na hinihiling ng isang leader democracy, mas malaki ang ating tsansang malutas ang ating mga problema sa pulitika, at magkakaroon tayo ng pagkakataong makamtan ang isang tunay at modernong demokrasya.

Department of Filipino, De La Salle University-Manila, Philippines

\section{Sanggunian}

Abueva, Jose Veloso, "Filipino Democracy and the American Legacy," in Annals of the American Academy of Political and Social Science, 428 (November 1976), 114-133. 
Anderson, Benedict, The Spectre of Comparisons: Nationalism, Southeast Asia and the World (London: Verso, 1998).

Bankoff, Greg, Crime, Society and the State in the Nineteenth-Century Philippines (Quezon City: Ateneo de Manila University Press, 1996).

Bendix, Reinhard, Max Weber: an Intellectual Portrait (New York: Doubleday \& Company, 1962).

Bolden, R.; Gosling, J., Marturano, A., and Dennison, P., "A Review of Leadership Theory and Compentency Frameworks," in LeadershipStudies.Com <http://www.leadership-studies.com>, 29 September 2009.

Breiner, Peter, Max Weber and Democratic Politics (Ithaca: Cornell University Press, 1996).

D'Andrade, Roy, The Development of Cognitive Anthropology (Cambridge: Cambridge University Press, 1995).

Dumont, Jean-Paul, "Far from Manila: Political Identities on a Philippine Island," in Anthropological Quarterly, 68:1 (January 1995), 14-20.

Eliaeson, Sven, "Constitutional Ceasarism: Weber's Politics in their German Context," in The Cambridge Companion to Weber, ed. by Stephen Turner (Cambridge: Cambridge University Press, 2000), 131-148.

Green, Jeffrey Edward, "Max Weber and the Reinvention of Popular Power," in Max Weber Studies, 8:2 (2008), 187-224.

Guillermo, Ramon, "Pantayong Pananaw and the History of Philippine Political Concepts," in Kritika Kultura, 13 (2009), 107-116, <www.ateneo.edu/kritikakultura>, 29 September 2009.

Harrison, Paul M., "Weber's Categories of Authority and Voluntary Associations," in American Sociological Review, 25:2 (April 1960), 232-237.

Kane, John \& Patapan, Haig, "The Neglected Problem of Democratic Leadership," in Public Leadership: Perspectives and Practices, ed. by Paul Hart and John Uhr,

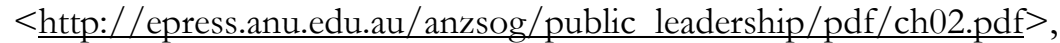
11 October 2009.

Kim, Sung Ho, "Max Weber," in Stanford Encyclopedia of Philosophy $<$ http://plato.stanford.edu/entries/weber/>, 10 October 2009.

Lassman, Peter, "The Rule of Man over Man: Politics, Power and Legitimation," in The Cambridge Companion to Weber (Cambridge: Cambridge University Press, 2000), 83-98.

McIntosh, Donald, "Weber and Freud: On the Nature and Sources of Authority," in American Sociological Review, $35: 5$ (October 1970), $901-$ 911.

Navarro, Atoy; Rodriguez, Mary Jane \& Villan, Vicente, eds., Pantayong Pananaw: Ugat at Kabuluban (Mandaluyong: Palimbagang Kalawakan: 1997).

Pakulski, Jan \& Higley, John. "Towards Leader Democracy?," in Public Leadership: Perspectives and Practices Hart, 45-54, $<$ http://epress.anu.edu.au/anzsog/public leadership/pdf/ch04.pdf>, 11 October 2009. 


\section{MGA MODELO NG PAMUMUNO SA PILIPINAS}

Palmer, Gary, Toward a Theory of Cultural Linguistics (Austin: University of Texas Press, 1996).

Paredes, Ruby, "The Origins of National Politics: Taft and the Partido Federal," in Philippine Colonial Democracy (Quezon City: Ateneo de Manila University Press, 1989), 41-69.

Parkin, Frank, Max Weber (London: Tavistock Publications, 1982).

Quinn, Naomi \& Strauss, Claudia, "Research on Shared Task Solutions," in $A$ Cognitive Theory of Cultural Meaning (Cambridge: Cambridge University Press, 1997), 137-188.

Reyes, Portia, "Pantayong Pananaw and Bagong Kasaysayan in the new Filipino Historiography: A History of Filipino Historiography as an History of Ideas," Unpublished Doctoral Dissertation (University of Bremen, 2002).

Ritzer, George, "Professionalization, Bureaucratization and Rationalization: The Views of Max Weber," in Social Forces, 53:4 (June 1975), 627-634.

Robertson, Tara \& Beasley, Duke, "Cognitve Anthropology," in Anthropological Theories: a Guide Prepared by Students for Students Web Page $<\underline{\text { http://www.as.ua.edu/ant/Faculty/murphy/436/coganth.htm }>, 24}$ September 2002.

Salazar, Zeus, Ang Babaylan sa Kasaysayan ng Pilipinas, in Bagong Kasaysayan: Mga Pag-aaral sa Kasaysayan ng Pilipinas, Vol. 4 (Quezon City: Palimbagan ng Lahi, 1995).

Salazar, Zeus, Kasaysayan ng Kapilipinuban: Bagong Balangkas (Quezon City: Bagong Kasaysayan, 2004).

Salazar, Zeus, "The Pantayo Perspective as a Discourse Towards Kabihasnan," in Southeast Asian Journal of Social Science, 28:1 (2000), 123-152.

Schneider, Andreas, "The Ideal Type of Authority in the United States and Germany," in Sociological Perspectives, 47:3 (Autumn 2004), 313-327.

Simbulan, Dante, The Modern Principalia: the Historical Evolution of the Philippine Ruling Oligarchy (Quezon City: University of the Philippines Press, 2005).

Smith, Warren Dupre, “The Philippine Question," in Economic Geography, 9:3 (July 1933), 303-320.

Thomas, J. J. R., "Weber and Direct Democracy," in The British Journal of Sociology, 35:2 (June 1984), 216-240.

Weber, Max, "The Profession and Vocation of Politics," in Weber: Political Writings, ed. by Peter Lassman and Ronald Spiers (Cambridge: Cambridge University Press, 1994), 309-369.

Weber, Max, "Bureaucracy," in Max Weber on Charisma and Institution Building, ed. by S. N. Eisenstadt (Chicago: University of Chicago Press, 1968), 66-77.

Weber, Max. "The Nature of Charismatic Authority and Its Routinization," in Max Weber on Charisma and Institution Building (Chicago: University of Chicago Press, 1968), 48-65. 
Weber, Max, "The Pure Types of Legitimate Authority," in Max Weber on Charisma and Institution Building (Chicago: University of Chicago Press, 1968), 46-47.

Weber, Max, "The Sociology of Charismatic Authority," in Max Weber on Charisma and Institution Building (Chicago: University of Chicago Press, 1968), 18-27. 